\title{
A EXPERIÊNCIA DE ESTUDANTES AFRICANOS NO BRASIL
}

\author{
Maria Lúcia Rodrigues Müller \\ Áurea Gardeni Sousa da Silva**
}

\section{RESUMO}

Este artigo pretende relatar os aspectos referentes a situações de racismo e discriminação racial vivenciada pelos estudantes dos Países Africanos de Língua Oficial Portuguesa (PALOP) que ingressaram nas Instituições de Ensino Superior Brasileiras através do Programa Estudante de Convênio de Graduação (PEC-G). Estabeleceu-se como objetivo neste trabalho compreender como é a experiência do estudante-convênio oriundo dos PALOP em duas capitais do Centro Oeste brasileiro, Brasília-DF, capital do país e Cuiabá-MT. Foram entrevistados alunos e ex-alunos da Universidade de Brasília (UnB) e da Universidade Federal de Mato Grosso (UFMT). Para a compreensão dos aspectos propostos as pesquisadoras recorreram às entrevistas em profundidade e à observação participante. Os dados obtidos informam que as universidades brasileiras não dispõem de estrutura para receber os estudante dos PALOP. Ademais, ser africano e negro no Brasil é uma experiência que impõe muitas dificuldades. Professores e colegas de curso pouco ou nada sabem sobre a realidade da África e reproduzem as percepções estereotipadas sobre o continente, circunstância incômoda para os estudantes. A prática das relações entre os alunos oriundos dos PALOP e os brasileiros é marcada também pelo racismo, discriminação e preconceito racial.

Palavras-chave: Estudantes africanos. PEC-G. Racismo. Discriminação racial.

\section{ABSTRACT}

\section{THE EXPERIENCE OF AFRICAN STUDENTS IN BRAZIL}

This article intends to report on issues related to racism and racial discrimination situations experienced by students of the Oficial Portuguese-speaking African countries (PALOP) who enrolled in higher education institutions through the Brazilian Exchange Program for Undergraduate Students - PEC-G (for its acronym in Portuguese). In this paper it was sought to understand the experience of PEC-G students who come from PALOP in two Brazilian Midwestern cities, Brasília-DF, the capital of Brazil and Cuiaba-MT, the capital of the State of Mato Grosso. Students and ex-students from the University of Brasília (UnB) and the Federal University of Mato Grosso (UFMT) were interviewed. In order to understand the proposed aspects, the researchers resorted to interviews and to the participating observation. The data

* Professora do Programa de Pós-Graduação em Educação da Universidade Federal de Mato Grosso (UFMT). Coordenadora do Núcleo de Estudos e Pesquisas sobre Relações Raciais e Educação da Universidade Federal de Mato Grosso (NEPRE/ UFMT).rodriguesmarialucia10@gmail.com

** Mestre em Educação pela Universidade Federal de Mato Grosso (UFMT). Pesquisadora do Núcleo de Estudos e Pesquisas sobre Relações Raciais e Educação da Universidade Federal de Mato Grosso (NEPRE/UFMT). cereusjamacaru@gmail.com 
reports that Brazilian universities do not have the structure to accommodate PALOP students. Moreover, being African and black in Brazil is an experience that imposes many difficulties. Teachers and students know little or nothing about the reality of Africa and reproduce stereotypical perceptions about the continent, which renders uncomfortable circumstances for these students. The relationship between PALOP students and Brazilian students is also stained by racism, discrimination and racial prejudice.

Keywords: African students. PEC-G. Racism. Racial discrimination.

\section{RESUMEN}

\section{LA EXPERIENCIA DE ESTUDIANTES AFRICANOS EN EL BRASIL}

Este artículo pretende relatar aspectos referentes a situaciones de racismo y discriminación racial vivida por estudiantes de países africanos de lengua oficial portuguesa (PALOP) que ingresaron en las instituciones de educación superior brasileras a traves del Programa Estudiante de Convenio de Graduación (PEC-G). Se estableció como objetivo en este trabajo comprender cómo es la experiencia del estudiante convenio oriundo de los PALOP en dos capitales del Centro Oeste brasilero Brasília-DF, capital del país y Cuiabá-MT. Fueron entrevistados alumnos y ex-alumnos de la universidad de Brasilia UnB y de la Universidad Federal Mato Grosso (UFMT). Para la comprensión de los aspectos propuestos las investigadoras recurren a las entrevistas en profundidad y a la observación participante. Los datos obtenidos informan que las universidades brasileras no disponen de estructura para recibir los estudiantes de los PALOP. Además, ser africano y negro en el Brasil es una experiencia que impone muchas dificultades. Profesores y colegas del curso poco o nada saben sobre las realidades de África y reproducen las percepciones estereotípicas sobre el continente, circunstancia incomoda para los estudiantes. La práctica de las relaciones entre los alumnos oriundos de los PALOP y los brasileros es marcada también por el racismo, discriminación y preconcepto racial.

Palabras claves: Estudiantes africanos. PEC-G. Racismo. Discriminación racial.

\section{Introdução}

A presença de estudantes estrangeiros nas universidades brasileiras parece esporádica e incomum, porém é amiúde e corriqueira. Os primeiros registros sobre estudantes estrangeiros no Brasil e de estudantes brasileiros em universidades de países latino-americanos remontam às primeiras décadas do século XX. Em 1917 registra-se a presença de brasileiros estudando no Uruguai; em 1919, estudantes argentinos, chilenos, paraguaios e uruguaios frequentavam cursos de nível superior no Brasil, inclusive na Escola Militar e na Escola Naval. A partir de 1964 o ingresso dos jovens de países latino-americanos, caribenhos, africanos e asiáticos foi regulamentado através do Programa Estudante de Convênio de Graduação (PEC-G). O PEC-G é o principal meio de ingresso de estudantes estrangeiros nas Instituições de Ensino Superior (IES) brasileiras. Até a década de 1970, os estudantes PEC-G eram oriundos especialmente dos países latino-americanos. Com a independência dos últimos países da África que ainda eram colônias na década de 1970, os estudantes dos países africanos foram incluídos no rol dos participantes do programa. A primeira década dos anos 2000 foi marcada pelo maior número de estudantes dos Países Africanos de Língua Oficial Portuguesa (PALOP) no PEC-G. O país recebeu mais 7.676 jovens como estudantes de graduação, e dentre estes 6.001 eram 
africanos, 1.636 latino-americanos e 39 asiáticos. Dos 6.001 estudantes provenientes de países africanos, 5.082 eram alunos dos PALOP. De Angola vieram 583 estudantes, de Cabo Verde, 2.657, da Guiné Bissau, 1.336, de Moçambique, 191 e de São Tomé e Príncipe, 315 (BRASIL, 2015). Kaly (2001) remonta ao século XIX a tradição de receber jovens de países africanos nas instituições de ensino brasileiras. Segundo o referido autor, já no século XIX os filhos e filhas de alguns dignitários angolanos e moçambicanos eram enviados para serem educados nas escolas do Rio de Janeiro.

O PEC-G é coordenado pelo Ministério das Relações Exteriores (MRE) e pelo Ministério da Educação (MEC), em parceria com Instituições de Ensino Superior. O programa faz parte da cooperação brasileira em educação inserida na política externa brasileira através da Cooperação Técnica entre Países em Desenvolvimento (CTPD). A CTPD é um acordo de parceria entre países semiperiféricos e periféricos, com vistas à promoção de ganhos mútuos e um instrumento da política externa brasileira. É uma das principais plataformas de relacionamento internacional brasileiro na atualidade (ULLRICH; CARRION, 2013).

A circulação desses estudantes está relacionada aos fluxos contemporâneos que possibilitam o trânsito de vidas entre países com diferentes fins, impulsionados por questões globais. A globalização aproxima países e sociedades distintas. Essa aproximação é celebrada através de relações políticas, comerciais, culturais e sociais, na busca da satisfação de interesses diversos, auxílio mútuo, trocas necessárias nas relações entre Estados. Dessa forma, torna-se possível compreender a relação entre celebração dos acordos educacionais e o trânsito de pessoas. Num mundo estreitado por relações comerciais, diplomáticas, pelo avanço da formas de comunicação tecnológicas, uma decisão que, muitas vezes, apresenta-se, primeiramente, como individual é impulsionada por questões mais amplas, além da esfera das decisões individuais.

Nessa medida, entre muitos sonhos e realidades colocados em trânsito, cabe olhar os estudantes dos países africanos em solo brasileiro com base na existência de relações supranacionais típicas de um mundo globalizado no interior de um jogo de relações que lhe é próprio. (GUSMÃO, 2012, p. 55).
O objetivo a que se propôs neste trabalho foi estabelecido em: conhecer a experiência dos estudantes dos países africanos a partir das universidades nas respectivas cidades de Brasília-DF - Universidade de Brasília (UnB) - e Cuiabá-MT - Universidade Federal de Mato Grosso (UFMT) - e o processo pelo qual ingressam nas Instituições de Ensino Superior (IES) brasileiras. Atualmente o PEC-G está firmado com mais de 57 países em pelo menos três diferentes continentes, porém a maioria dos estudantes ingressantes na última década era dos PALOP. Dada a provisoriedade do grupo, não foi possível estabelecer um recorte temporal, mas é possível assegurar que os entrevistados ingressaram entre os anos de 2005 e 2010 . Em ambas as universidades dialogamos com estudantes de outros países africanos participantes de outros programas, mas definimos como sujeitos da pesquisa estudantes dos PALOP participantes do PEC-G. Ainda que Moçambique e São Tomé e Príncipe sejam PALOP, não encontramos estudantes dessas nacionalidades no PEC-G ainda vivendo no Brasil. Os estudantes dessas nacionalidades que participaram do programa já haviam regressado a seus países.

De acordo com Becker (1999), cada pesquisador pode desenvolver métodos que respondam aos problemas que surgem em sua pesquisa. Isso não quer dizer que o que já foi criado antes deva ser ignorado, porém, diante da possibilidade de surgimento de problemas específicos do caso pesquisado, é necessário que se crie meios de respondê-los que talvez as teorias já inventadas não deem conta. Assim, ao considerar as exigências específicas colocadas por esta pesquisa, resolvemos conciliar, além dos documentos, a entrevista em profundidade e a observação participante como técnicas de coleta de dados.

A opção pela entrevista em profundidade se deve à "sua importância para obter informações sobre realidades sociais, pela maior flexibilidade e por permitirem ao entrevistado construir suas respostas com mais liberdade diante do entrevistador" (OLIVEIRA; MARTINS; VASCONCELOS, 2012, p. 01).

Oliveira, Martins e Vasconcelos (2012) asseguram que, mesmo diante da possibilidade da presença do entrevistador influenciar o entrevistado, a entrevista em profundidade é a que possibilitará a 
exploração dos pontos de vistas dos atores sociais inseridos nos contextos de investigação. De acordo com Poupart (2008 apud OLIVEIRA; MARTINS; VASCONCELOS, 2012, p. 02), é através da entrevista do tipo qualitativo que se poderá proceder: 1) a análise das realidades sociais segundo a perspectiva dos envolvidos, indispensável à apreensão e compreensão das condutas sociais; 2) denunciar preconceitos, práticas discriminatórias e iniquidades, porque abre a possibilidade de compreender e conhecer internamente os dilemas e questões enfrentados pelos atores sociais; 3) por ser uma ferramenta de informação sobre as entidades sociais, capaz de elucidar as realidades sociais, mas, principalmente, por ser um instrumento privilegiado de exploração da experiência dos atores sociais.

A entrevista em profundidade se apresenta como o método mais adequado aos objetivos do trabalho, especialmente pela possibilidade de oferecer percepções detalhadas a partir de pontos de vistas individuais e pela necessidade de explorar temas sensíveis e coletar dados essencialmente subjetivos, os quais se relacionam com os valores, as atitudes e as opiniões dos sujeitos entrevistados. Em outras palavras, a entrevista em profundidade é a mais adequada quando o objetivo é a obtenção de um conhecimento intersubjetivo e compreensivo (OLIVEIRA; MARTINS; VASCONCELOS, 2012). Considerando a necessidade de anonimato, bem como de assegurar abrigo às palavras dos entrevistados, os estudantes serão identificados por número, da seguinte forma: E1B, onde: E estudante; 1 - identificação numérica em ordem crescente; B - Brasília; C - Cuiabá.

A observação participante como técnica de coleta de dados é considerada complemento às entrevistas. Minayo (2007) afirma que, por captar formalmente a fala, a entrevista, quando analisada, precisa incorporar o contexto da sua produção e, sempre que possível, ser acompanhada e complementada por informações provenientes de observação participante. A combinação das entrevistas com a observação participante pode oferecer dados robustos para serem analisados. De acordo com Minayo (2007), há aspectos da experiência vivida que são melhor compreendidos com a combinação da entrevista e da observação, uma vez que a entrevista é a narrativa das experiências dos entrevistados e a observação será o olhar do pesquisador sobre tais experiências.

Quando conhecemos os estudantes, as principais perguntas foram: quem são? Como vêm ao Brasil? Por que escolhem o Brasil? Como é viver no Brasil, nas cidades onde vivem? Como é a experiência na universidade? E considerando o debate sobre relações raciais no Brasil: como é a relação com os brasileiros? Há racismo? Há preconceito? De certa forma, essas perguntas, também feitas pelas pessoas comuns no dia a dia, impulsionaram a pesquisa.

Sendo os países africanos dos quais os estudantes são provenientes de língua oficial portuguesa, a permanência em nosso país para fins de estudo é fruto de acordos bilaterais no âmbito educacional, como o PEC-G. Os convênios de cooperação educacional influem na decisão do estudante no momento de escolher um país para estudar de maneira diferencial de acordo com o país de origem (OJIMA et al, 2014). No caso, uma das motivações que levam esses estudantes a escolherem o Brasil é justamente o fato de ter o português como língua oficial.

$\mathrm{Na}$ aproximação com os países africanos no âmbito da política externa, o Brasil se apresentava como uma sociedade multirracial, de considerável população negra e um caso modelar de relações raciais. Nesse contexto, o país era apresentado como possuidor de uma natural vocação e afinidade com a África. Enfatizava-se a familiaridade e a história comum entre Brasil e África e apresentava-se um esforço transparente em construir uma imagem negra do país (SARAIVA, 2012). Conforme Teixeira (2006) ressalta, a imagem que os estrangeiros em geral passam a ter sobre o Brasil, e que perdura até os dias de hoje, é a visão da harmonia racial.

A perspectiva da imagem de um Brasil racialmente democrático projetada internacionalmente é afirmada por Penna Filho (2009). De acordo com este autor, na ocasião da aproximação brasileira dos países do continente africano via política externa, o Brasil já tinha um contundente discurso contrário à discriminação racial, ao mesmo tempo em que se ostentava como exemplo de convivência racial para o mundo, fazendo sempre questão de expor essa característica, tanto interna quanto externamente. 
Contudo, na realidade vive a prática da exaltação ao chamado mundo ocidental (ou civilização ocidental), facilmente identificada com os valores emanados da Europa Ocidental e dos Estados Unidos. Entretanto, a título de projeção do país no plano internacional, evocam-se frequentemente as características, apresentadas como exemplares de bom convívio entre as raças, que supostamente existiam no Brasil (PENNA FILHO, 2009).

A política externa brasileira com a África e, especialmente, com os PALOP se fundamenta no argumento da identidade e dos vínculos linguísticos, culturais e históricos compartilhados. Os PALOP são os países do continente africano com os quais o Brasil mantém um relação mais estreita, uma relação em que o idioma é apontado como o responsável por uma maior proximidade histórica e cultural. Em consequência, declara-se uma natural aproximação entre Brasil, Angola, Cabo Verde, Guiné Bissau, Moçambique e São Tomé e Príncipe.

Os textos, discursos e publicações a partir dos quais o MRE brasileiro se projeta aos PALOP produziram a formação de uma imagem do país. A imagem formada no contexto dessa aproximação enfatiza principalmente os vínculos históricos, culturais e linguísticos entre o Brasil e os PALOP. Em tal discurso, além laços Brasil e PALOP seriam países irmãos. Nesta conjuntura, buscou-se divulgar a imagem de um país em que prevalece a democracia racial e que culturalmente se assemelha à África. Os objetivos no continente africano foram principalmente de projetar a imagem de um poder tropical e industrial, que um dia tinha sido colônia, convencendo os Estados africanos de que as relações históricas do Brasil com Portugal não inibiriam o desenvolvimento das relações com os países da região (NOSOLINI, 2004).

\section{Por que o Brasil?}

Aliado aos vínculos linguísticos e históricos, a imagem de país majoritariamente negro e racialmente democrático é que impulsiona a escolha de muitos estudantes dos PALOP pelo Brasil. O curso superior é uma possibilidade de qualificação para o que se considera as melhores oportunidades. Fazê-lo num país diferente do seu é motivado, por um lado, pela fragilidade dos sistemas de ensino superior nacionais e por outro, pelo status atribuído àqueles que estudaram fora.

No momento da opção pelo Brasil como destino de estudos foi preponderante o imaginário sobre $\mathrm{o}$ país. Mesmo para aqueles para quem o país foi uma questão de ocasião, ainda se fez relevante o forte imaginário sobre o país e sobre o povo brasileiro. A imagem do Brasil e dos brasileiros como lugar e povo festivo foi recorrente entre os entrevistados. As alusões ao carnaval e ao futebol foram frequentes, além da imagem de país eminentemente negro.

Os estudantes citaram como principal fonte de informações sobre o país a televisão. Para eles o imaginário se divide em duas perspectivas, nas quais o Brasil é um país violento ou um paraíso. A imagem do Brasil como um lugar perigoso, de prostituição, tráfico e violência, onde, a qualquer momento e em qualquer lugar, se possa ser assaltado, é decorrente da exibição de programas intitulados jornalísticos, como o Cidade Alerta (HIRSCH, 2007). E de acordo com Amaral (2013), a presença brasileira se amplia quando consideradas as influentes telenovelas, transmitidas especialmente nos PALOP.

A superidealização é uma das razões do desapontamento com a realidade com a qual se deparam ao chegar ao Brasil. Tal situação expõe a fragilidade das informações a partir das quais é construído o sonho de estudar no país. Percebe-se que, em todo o processo preparatório, os estudantes não têm a oportunidade de construir um corpo de conhecimentos mais sólido acerca da realidade brasileira e da imensa diversidade geográfica, social, cultural e econômica.

A partir das descrições sobre o Brasil feitas pelos estudantes, pode-se entrever, como apontado por Teixeira (2006) e Penna Filho (2009), a tendência na qual o país se projeta internacionalmente como lugar de pacífico convívio racial, de maioria negra e diretamente ligado à África. Alguns estudantes declararam ter escolhido o Brasil por acreditarem ser este um país eminentemente negro e, ainda, sem racismo, ou seja, a visão que os estudantes tinham do Brasil estava diretamente relacionada ao mito da democracia racial (TEIXEIRA, 2006).

Conforme Teixeira (2006) ressalta, a imagem que os estrangeiros em geral passam a ter sobre o Brasil, e que perdura até os dias de hoje, é a visão 
da harmonia racial. Essa visão teria como principal fonte o mito da democracia racial, que é a crença de que o Brasil é um país mestiço e sem conflitos raciais; de que a escravidão teria sido benigna; e, por fim, de que o desenvolvimento econômico haveria de desmanchar os resíduos do preconceito e do racismo e promover a inclusão da população negra no país (JACCOUD; BEGHIN, 2002).

A partir das entrevistas é possível estabelecer que quando os estudantes se integram à sociedade brasileira, passam a perceber o que o autor Penna Filho (2009) chama de "exaltação ao mundo ocidental" por parte dos brasileiros. Na entrevista a seguir o estudante afirma haver distinções explícitas entre o tratamento dispensado a um africano e a um europeu. Segundo o estudante, os brasileiros seriam mais atenciosos, receptivos, cordiais e disponíveis com europeus e americanos.

Você vê a diferença de tratamento entre um africano e um europeu. Então, quando tem um europeu lá, a diferença de tratamento. Ele admira o americano, então ele trata melhor um americano do que uma cara que não é, porque eles pensam que africano não é gente não. (E, 1, B),

\section{Racismo, preconceito e discriminação racial}

As situações pelas quais os estudantes dos PALOP passam em sua permanência no Brasil não oferecem alternativas que não seja qualificá-las de ocasiões nas quais atuaram o racismo, a discriminação e o preconceito racial, ou os três conjuntamente. É consenso entre as pesquisas realizadas sobre estudantes africanos no país a manifestação do significado da "raça" no Brasil (GUSMÃO, 2012). A presença desse estudante evidencia o significado da "raça" na realidade brasileira, visto pela cor da pele e pelas relações que se estabelecem com o chamado "outro", brasileiro ou estrangeiro, porém negro também (GUSMÃO, 2012). As características que poderiam facilitar sua inserção na sociedade brasileira acabam por, frequentemente, se tornarem um dado mais negativo do que positivo. Isso porque, de acordo com Hirsch (2007), sobre os negros e mulatos nacionais recaem pesados estigmas, inclusive a imediata associação entre essas pessoas e a classe mais baixa da sociedade, assim como a assaltantes. Desta forma, os estudantes acabam por ser afetados, em muitas situações, pelos mesmos estigmas reservados ao negro brasileiro (HIRSCH, 2007). A projeção desse estigma é tão forte que muitas vezes os negros são vistos como "favelados" e "assaltantes", e assim também o são os estudantes (HIRSCH, 2007).

Uma das estudantes entrevistadas nos informou que chegou a ser revistada no interior de uma loja no centro de Cuiabá. Nesse sentido, o ideário racista presente na sociedade brasileira a tirou da condição privilegiada de estudante universitária para posicioná-la na marginalidade.

Um dia eu fui à loja Marisa, assim, cheguei, entrei no Centro. Naquela loja no Centro. Cheguei, entrei, eu vi, eu estava, eu andei na loja, só que eu não queria comprar. Não vi nada que me interessou a comprar. Quando eu estava saindo da loja... Estava saindo e uma loira bem branca, no momento que eu fui sair, apitou, aquele que, quando você rouba na loja, que apita aquela coisa. O segurança fez questão de me chamar e não chamou a branquela, digamos. Eu falei: 'não estou com nada na bolsa.' Ele falou: 'você pode me acompanhar?' Eu falei: 'não'; estava com a consciência tranquila. Eu me senti tão constrangida, eu fiz questão de abrir minha bolsa e ele viu que não tinha nada. Ele me pediu desculpa, eu sai e fui embora. Eu fiquei tão chocada, mas tão chocada... Demorei para entrar naquela loja. Essa aqui é para nunca mais esquecer. Eu falei: 'como é que pode um país tão negro ser tão preconceituoso que é o Brasil.' Eu fiquei constrangida, eu falei: 'nunca pensei que eu poderia sofrer um preconceito tamanho', porque dizem que a Europa é bem preconceituosa, agora, o Brasil eu não esperava. Eu fiquei surpresa. Brasil é muito preconceituoso, muito. (E, 12, C).

A experiência acima relatada contraria a imagem internacionalmente projetada de país racialmente democrático e isento de conflitos raciais. $\mathrm{Na}$ sociedade brasileira, os negros são os mais afetados pela desigualdade social, que é uma das faces da discriminação racial no país (JACCOUD; BEGHIN, 2002). Tais desigualdades repercutem em situações como a vivenciada pela estudante, nas quais pessoas negras são vistas como propensas à criminalidade. As desigualdades sociais brasileiras, que para Paixão (2003) têm surpreendentes fundamentos raciais, são uma evidência da discriminação racial no Brasil. Jaccoud e Beghin 
(2002) afirmam que, no Brasil, a discriminação racial perpassa todas as esferas da vida social. A cor das pessoas é um determinante importante e a discriminação racial parece estar presente em todas as fases do ciclo de vida individual. A partir do que dizem essas autoras, é possível afirmar que há uma perpetuação, ao longo de décadas, de um processo ativo de discriminação de indivíduos em razão da cor, que opera em diferentes esferas da vida social. Paralelamente, a reprodução de preconceitos e estereótipos raciais legitima os procedimentos discriminatórios.

Tal perspectiva contraria a mais comumente propagada percepção sobre o Brasil, segundo a qual este seria um país mestiço, sem conflitos raciais. Conforme Teixeira (2006), a sociedade brasileira, comumente declarada como não racista, tem um padrão peculiar de relações raciais. A experiência dos estudantes atestam o prisma segundo o qual a sociedade brasileira tem uma forma própria de discriminar:

Meio que existe o racismo brasileiro, é meio escondido, entendeu? O cara faz você perceber. O cara faz, mas é meio escondido, entendeu? Você vê até pela questão quando eu cheguei aqui. Você vê até pela questão do negro. (E, 5, B).

O preconceito racial contra negros praticado no Brasil é de um modelo diferente do preconceito racial de outros países: para nós, o preconceito racial manifesta-se pela aparência dos indivíduos - cor da pele e traços físicos, em geral chamado de preconceito de marca; já o preconceito nos Estados Unidos refere-se à ascendência, seria o preconceito de origem (NOGUEIRA, 1955 apud TEIXEIRA, 2010). A autora afirma que é próprio do "racismo à brasileira" discriminar de forma sutil sem parecer que está discriminando (TEIXEIRA, 2010, p. 22). É próprio da sociedade brasileira o preconceito de "marca", para a qual, quanto mais evidente o fenótipo, quanto mais a aparência for negra, maior será o preconceito (MÜLLER et al, 2009).

Muller e colaboradores (2009) afirmam que o preconceito contra a população negra no país se origina num processo histórico que pretendeu manter os negros brasileiros como cidadãos de segunda categoria. Tal processo se deu através da difusão de centenas de imagens negativas contra as pessoas negras. Ao longo de todo o século XX, as escolas de formação de professores, os livros didáticos e outros meios de comunicação (o rádio, a televisão, a literatura) ou outras agências sociais foram responsáveis por difundir uma imagem negativa do negro. A reprodução dos estereótipos construídos ainda no século XIX foi extensa e sutil, e, portanto, mais difícil de combater. A partir desse quadro é possível dizer que o imaginário social brasileiro é racista. Ainda temos marcas do período escravista, que conferia imaginária e concretamente a pessoas de pele mais clara os sentimentos de maior importância e superioridade em relação às pessoas de pele mais escura. Cristalizou-se na memória social e, portanto, no imaginário uma representação negativa contra a população negra. Muitas vezes quem tem a pele mais escura é tratado como se fosse inferior, inferior na inteligência e nos valores morais (MÜLLER et al, 2009). Em contrapartida, havia o permanente elogio a brancos europeus, ou a tudo o que se referia à Europa, enquanto "o esquecimento" da África e dos africanos, ou sua apresentação como atrasados e boçais, negava sua contribuição para a construção do Brasil e consubstanciava-se como outra maneira de inferiorizar esse grupo (MÜLLER et al, 2009).

Uma das dificuldades apontadas no processo de adaptação, segundo a percepção dos estudantes, foi uma tendência, em certo momento, que indicava a preferência dos brasileiros por interagirem com europeus. Conforme afirma este estudante, as pessoas estariam mais interessadas em eventos relacionados aos países da Europa do que naqueles relacionados aos países africanos, assim como pessoas de ascendência europeia ou estadunidense eram melhor tratadas, recebendo mais atenção, inclusive por parte dos professores. O falar português com um sotaque diferente, nestes casos, era apreciado, diversamente do que ocorria com os estudantes africanos. Para o estudante, a supervalorização de europeus e americanos implica diretamente numa baixa estima dos brasileiros.

É quando tem, porque quem organiza semana da Europa aqui são algumas embaixadas, porque o meu curso tem quase 19 habilitações. Tem a semana francófona, francofonia. Então você vê, é lotado, porque todo mundo quer saber o que está acontecendo. Quando tem Ucrânia, é lotado. Mas quando a gente 
tenta organizar a semana da África, a gente faz toda a divulgação, manda para... éééé... por exemplo, para área de comunicação, para publicar no site da universidade. Eles publicam só quando o negócio está acontecendo. Dia da África é dia 25 de maio, eles vão publicar só dia 26. A gente cola cartaz no corredor da universidade, ninguém aparece. $(\mathrm{E}, 1, \mathrm{~B})$.

Eu não sei, porque na turma, quando tinha um francês, então todo mundo chamava ele logo. Você vê que há diferença de tratamento entre um africano e um europeu. Então, quando tem um europeu lá, a diferença de tratamento, até com professor, para perguntar, tenta falar a língua do cara. Perguntar se o cara entende. Então, esse tipo de tratamento não é feito conosco. (E, 1, B).

Com Europa, americanos do que africanos. Com africanos não, eu não estou falando só de mim. Porque nós criamos aqui a união dos estudantes africanos. Essa é uma queixa de todos os africanos. Eu não estou aqui para falar de todo mundo, para ser porta voz, mas são coisas que a gente passa aqui, que passamos aqui na universidade. Então, essa questão, até essa, até às vezes nós falamos: 'brasileiros têm problemas de autoestima', que ele admira coisas que vêm de fora. Ele admira o americano, então ele trata melhor um americano do que uma cara que não é, porque eles pensam que africano não é gente não. Então eu faço letras, veio em minha sala pessoas do Japão, França, de outros países que vêm para fazer um intercâmbio aqui. Então, às vezes, quando encontra essas pessoas, por falar um sotaque do inglês, do português ou francês, o brasileiro acha bonito, entendeu. Essas pessoas são muito protegidas pelo aluno e professor. Então nós vimos de um tipo de ensino muito diferente que aqui, nosso português. E eles não dá preocupação para ver se a gente está entendendo a matéria, essas coisas assim. (E, 1, B).

A partir de um conjunto de pesquisas realizadas no Núcleo de Estudos e Pesquisas sobre Relações Raciais e Educação (NEPRE), ficou evidente que, quanto mais escura era a cor da pele, mais exposta a situações de discriminação velada ou explícita estaria a pessoa. Persiste a permanência de um ideário racista, produzido ainda no século XIX, definidor das relações entre brancos e negros na sociedade brasileira, Uma situação bastante significativa vivenciada por um estudante corrobora a existência e continuidade desse ideário racista. No episódio relatado, o estudante viu os compa- nheiros serem identificados como "preto azul" em Cuiabá;

Porque africanos para eles é tudo o que for preto, entre aspas, que eles falam 'preto azul', entendeu? Nisso eu tinha ligado para os meninos para irem lá, né. Era aqui no bairro mesmo, que eu estava lá. Nisso o povo pensou que eu era brasileiro. Então começaram a comentar entre eles: 'Nossa, olha a cor daquele cara, preto azul', tá entendendo, nem adianta falar. Então começaram a rir deles. Eles estavam de longe chegando, entendeu? (E, 2, C).

As situações vivenciadas pelos estudantes apontam manifestações simultâneas de racismo, preconceito e discriminação racial. De acordo com Kaly (2001) e Subuhana (2005), o preconceito racial é a principal causa do mal-estar em terras brasileiras; e ser universitário e estrangeiro atenua a experiência negativa da discriminação racial. $O$ trecho da entrevista a seguir exemplifica uma situação na qual os estudantes foram acolhidos porque foram percebidos como estrangeiros em decorrência do sotaque:

Mas uma coisa que eu percebi, o preconceito, o racismo aqui no Brasil, sim, existe, mas quando eles percebem. Estou falando realmente de Brasília e Uberlândia, que eu tive experiência. Quando eles percebem que você é estrangeiro, de certa forma você não passa por esse tipo de coisa. O preconceito é muito mais forte entre os brasileiros em si, assim que eu percebo. Uma vez eu fui para Uberlândia, estava eu, meu amigo e um brasileiro, todos éramos negros. A gente ficou lá, chegou um cara brasileiro, tentando, conversando com a gente e logo quando ele percebeu que outro amigo, ele não é estrangeiro, falou pra ele: 'Vai para o seu canto que eu vou conversar com eles.' (E, 6, B).

Tal como os negros no Brasil, os estudantes africanos são identificados por brasileiros pelas categorias por eles detestadas: "moreninho", "neguinho", "sangue bom" e "angolano"; e pelas categorias "assimilado", "muzungo", "mulungu" e/ou "mucunha" (SUBUHANA, 2005). Ou ainda por termos embranquecedores como "moreno" e "morena". Conforme se verifica nos depoimentos a seguir, as estudantes percebem a tendência de serem chamadas por termos embranquecedores, tendência originada no receio de "ofender". Esse padrão é característico da etiqueta das relações ra- 
ciais brasileiras, na qual as pessoas usam palavras embranquecedoras para se referirem às pessoas negras que lhe são próximas.

Fala morena, não fala que é negra não, fala mulata. $\mathrm{Eu}$ acho que as pessoas pensam que chamar uma pessoa de negra é ofender. Tem muitas pessoas que acham que chamar uma pessoa de negra é ofender a pessoa. Por isso que muitas pessoas preferem chamar de morena. Que acha que você vai se ofender se falar que você é negra. Eu não me ofendo. (E, 13, C).

Não, assim, tem aquela coisa que criaram aqui para não ofender. Eu sei, eu sei que eu sou preta, só que aqui criaram aquele negócio de chamar a pessoa de morena para não ofender. Para que a pessoa não se sinta ofendida. Eu tenho ciência de que eu sou negra, não precisa. $(\mathrm{E}, 9, \mathrm{C})$.

As discriminações parecem afetar homens e mulheres de maneiras diferentes. Hirsch (2007) e Nunes (2013) apontam as abordagens policiais como algumas das situações que se tornam corriqueiras para os estudantes, similarmente a serem evitados como se fossem assaltantes. Tal fato não ocorre com as estudantes; as mulheres estão mais sujeitas ao isolamento. Conforme os depoimentos a seguir, tornou-se lugar comum os estudantes serem evitados ou verem as pessoas se apegarem a seus pertences quando os percebiam, ou ainda se esquivarem deles ao vê-los se aproximar. Os depoimentos dos estudantes contrariam o senso comum brasileiro, segundo o qual não haveria preconceito de cor no país, e sim de classe social, visto que mesmo usando trajes sociais que indicam boas condições financeiras e frequentando espaços sociais elitizados, foram discriminados. No entendimento do estudante do segundo depoimento, dentre as principais razões pelas quais as pessoas associam o negro à criminalidade estariam os programas "jornalísticos" que insistem em alardear os crimes cometidos por pessoas negras e não destacam na mesma proporção os crimes cometidos por brancos. Outro fato que corrobora a existência do preconceito de cor é o registrado por Fannon (2008), no qual os estudantes tiveram suas companhias rejeitadas em transportes coletivos, situação que também aparece nos depoimentos:

Então, até a gente sofre esses mitos que chega aqui, a gente chega no ônibus, até quando você está lá, não é todo mundo que vem sentar perto de você. Então é isso, eu venho, morava aqui perto da universidade, você vinha todo dia, pessoas olhavam você de um jeito. Quando via você, pegava bolsa para esconder, até na casa mesmo de professores da UnB. Porque UnB tem várias casas. Eu... o tio da minha mulher, ele é professor aqui na UnB. Mora lá na UnB. Então eu fui lá um dia para esperar ela para ir para a festa. Eu estava muito bem vestido, mas a mulher chegou perto de mim e gritou como se fosse uma coisa. Então eu fiquei lá e ela chamou a segurança para mim. E a segurança falou que a mulher disse que eu estava espantando ela. (E, 1, B).

$\mathrm{Eu}$ não passo por muita discriminação. Eu passei uma, quando fui a Goiânia. A gente foi sacar o dinheiro com um amigo meu. Tinha... acho que foi 18 horas, tinha uma família dentro, viu a gente chegar, ficaram no canto. A gente sacou o dinheiro, quando a gente saiu, eles voltaram para fazer as transações deles. Então o meu amigo falou: 'eu já estou acostumado com isso.' Essas coisas, ele já está acostumado. Eu falo: 'não', mas eu ia seguir eles e brigar com eles. Ele falou: 'não, deixa para lá, o povo aqui age assim.' Mas do outro lado também eu não dou culpa para essas pessoas. Vamos ver, a mesma coisa que eu te falei da mídia. Você já sentou na televisão na Globo ou na Record? Vê aquele Cidade Alerta falando de um cara branco que fez crime? Não! A maioria que passa são os negros, negros, negros. Então as pessoas quando veja isso, pensa que todo negro é criminoso, todo negro não estuda. (E, 6, B).

Eu já passei discriminações aqui. Uma dessas cenas... uma vez uma senhora deixou cair uma pochete com moedinhas e eu apanhei e fui entregar a ela. E ela simplesmente pôs-se a correr. E tinha um cara no edifício, lá no terceiro ou quarto andar, que viu a situação. Desceu e veio a ver comigo e eu falei: 'não, eu só queria entregar.' 'Não, eu vi.' Ele pegou da minha mão e foi entregar. E a senhora veio e pediu desculpa. Eu disse: 'não, tudo bem.' Já estive na calçada, a andar, e estava vindo uma pessoa na minha direção e teve que trocar a bolsa de lugar, teve que apertar bolsa. Já dei lugar no ônibus para senhoras que não aceitavam sentar, já fui olhado mal. Já tem gente que, o ônibus cheio, e tem cadeira do meu lado, e não se sentou, porque não pode sentar ao lado de um negro. $(\mathrm{E}, 4, \mathrm{~B})$.

Mas às vezes, cara, eu já fiquei triste, triste mesmo. $\mathrm{Eu}$ entrei no ônibus, acho que foi ano passado. Eu entrei no ônibus, indo para o CPA III, quando eu 
entrei, o ônibus estava cheio. Eu fui, entrei, vou ficar num lugar lá. Nesse lugar já tinha uma senhora lá e ela é negra, quando eu cheguei lá, ela saiu de lá. Ela saiu, foi sentar no outro lugar lá. Às vezes, quando sento no ônibus, eu sento, ninguém senta no outro banco que tá ao lado. Às vezes, nem todos fazem isso, porque não vou falar, não vou generalizar todos. Alguns. Alguns fazem isso. (E, 9, C)

E no ponto de ônibus, quando chegamos, chegamos nós quatro, três meninos. Rapaz, as pessoas que estavam no ponto de ônibus, assim, simplesmente mudaram de lugar, foram pra outro lugar [sobre situação vivida em Florianópolis]. (E, 11, C).

Ao ingressarem na sociedade brasileira e passarem a lidar com esse quadro, há um confronto com a perspectiva sobre si mesmos e sobre pessoas negras de maneira geral. Aqui passam a ser identificados e associados com um grupo social estigmatizado.

E outra coisa também que a gente percebe, quando você anda pela universidade, todo mundo corre de você. Então criaram um mito na sociedade de que o negro é bandido. Então até a gente sofre esses mitos, que chega aqui. A gente chega no ônibus, até quando você está lá não é todo mundo que vem sentar perto de você. Não é todo mundo que chega lá. $(\mathrm{E}, 1, \mathrm{~B})$.

De maneira geral, esse contexto nada tem a ver com as próprias representações dos estudantes. Segundo Hirsch (2007), nas sociedades de origem esses jovens fazem parte de um seleto grupo, que chegou ao nível superior. Alguns são, de fato, filhos de uma elite econômica. Esses jovens pertencem ou têm a expectativa de em breve pertencer a um grupo privilegiado em seus países de origem, o que gera um curto-circuito quando aqui chegam, uma vez que se deparam com o status inferiorizante que é atribuído aos brasileiros identificados como negros e mulatos, status que, por empréstimo, é atribuído também a eles. Em outras palavras, esses estudantes que fazem parte de uma elite ou que se encontram em processo de ascensão social são obrigados a lidar com o estigma que paira sobre os negros brasileiros, na medida em que, não raro, são assim identificados à primeira vista. Em nossa sociedade, via de regra, os negros são vistos como pobres e incultos, dado que essa atribuição de pobreza e incultura é naturalizada no senso comum e no quotidiano das relações sociais. Os estudantes são, pois, obrigados a lidar com um status inferio- rizante que lhes é naturalmente atribuído em razão da cor da pele (HIRSCH, 2007).

Um dos estudantes, quando questionado sobre o que pensava sobre racismo, discriminação racial e preconceito no Brasil, confirmou que havia sido informado que poderiam passar por situações de discriminação e preconceito racial. No parecer do estudante, o racismo brasileiro e a discriminação no país são discretos, porém mais excludentes e mais perigosos. $\mathrm{O}$ estudante observou que via negros em danças e jogos de futebol, porém não via negros na universidade. Em todo o curso não havia mais que um professor negro. Para ele, no Brasil, os negros têm um lugar e a temática do racismo é muito presente.

Sim, vocês vão passar por situações meio chatas, mas quando você chega aqui, meio que existe o racismo brasileiro, é meio escondido. O cara faz, você percebe. O cara faz, mas é meio escondido. Você vê até pela questão quando eu cheguei aqui. Você vê até pela questão do negro. A gente, até quando está lá em Angola, vê negro dançando samba, jogando futebol, mas quando você vem aqui. Eu falei que já fui em outros países, você não vê o negro. Onde que está o negro? Quando eu cheguei aqui, em 2010, praticamente, estava na fase de inclusão de negros, desse negócio de cotas; quando eu cheguei na sala, você não vê. Eu nunca tive aula com nenhum professor negro. O negro brasileiro que parece que eu tive aula é só um, mas eu já estou quase terminando meu curso. Você sente que é um racismo. É uma instituição, que não é mais aquele pessoal, mas é estrutural. Você sente que é mais poderoso, entendeu? Então eu falo que o racismo brasileiro, ele exclui. Não é igual o cara falar: 'eu não gosto de você.' Você sabe bem o que o cara está falando. Aqui é meio que escondido, aqui é excludente. Você não vê o negro na televisão, você não vê. Na universidade você não vê negro. A representação do negro é meio que... o cara só joga futebol, dança, só. Meio que tem um lugar, negro no Brasil tem um lugar, porque negro no Brasil tem um lugar. A gente fala que você vê um cara andando. $\mathrm{O}$ cara de outro lugar vai saber que é negro brasileiro. (E, 5, B).

Kaly (2001), sociólogo senegalês que já foi estudante de convênio no Brasil, afirma que o racismo e a discriminação baseada na tonalidade da cor da pele estão sempre na vida cotidiana. O estudante universitário tem sempre que mostrar ou provar que 
não é "aquele que pensam que é" (KALY, 2001).

Segundo Teixeira (2006), integram o jeitinho brasileiro de discriminar os diferentes graus de rejeição ao negro, que pode ir desde a "relativa" aproximação social, estabelecida nos momentos de lazer, ao estreitamento de laços de amizade, por exemplo, até o completo afastamento, representado pelas proibições de casamento. Os estudantes-convênio africanos não relataram episódios de discriminação na interação com os colegas de curso. Contudo, a aproximação para a construção de laços de amizade só ocorria após a demonstração de excelentes desempenhos por parte dos estudantes africanos. Ou seja, eles afirmam que só passaram a ser procurados pelos brasileiros quando estes necessitavam de auxílio em disciplinas nas quais os estudantes africanos tinham excelentes notas. $\mathrm{Na}$ situação inversa, ou seja, quando precisavam de auxílio em disciplinas como língua portuguesa, não recebiam o mesmo apoio dos estudantes brasileiros. Um dos estudantes observa que a atenção dada aos europeus não era a mesma dispensada aos africanos. Ele afirma perceber que há mais atenção, tanto de alunos como de professores, com estudantes europeus.

Eu não sei, porque, porque na turma, quando tinha um francês, então todo mundo chamava ele logo. Você vê que há diferença de tratamento entre um africano e um europeu. Então, quando tem um europeu lá, a diferença de tratamento, até com professor, para perguntar, tenta falar a língua do cara. Pergunta se o cara entende. Então esse tipo de tratamento não é feito conosco. (E, 1, B).

Kaly (2001) afirma que a cor da pele é um elemento homogeneizador dos estudantes para os brasileiros. Conforme o sociólogo, a cor negra expõe os estudantes aos mesmos tratamentos dispensados aos negros brasileiros:

[...] essa mesma cor já os coloca nas camadas sociais mais inferiorizadas, mais humilhadas e hostilizadas da sociedade brasileira: os pretos nativos. Quem são esses pretos nativos? Pessoas vivendo à margem da cidadania. Pessoas perifericamente integradas à sociedade brasileira. Os estudantes africanos pretos recebem, basicamente, os tratamentos dispensados aos pretos brasileiros; isto é, são tratados como se fossem necessariamente pessoas pobres, analfabetas, perigosas, faveladas, ignorantes. Os tratamentos racistas, inferiorizantes e estereotipados, que fazem parte da vida quotidiana dos estudantes pretos, são dispensados por brasileiros de todas as camadas sociais e de todas as tonalidades de pele. (KALY, 2001, p. 113).

As referências aos estudantes muitas vezes se alternam entre a mistificação, a mitificação e o exotismo. É possível afirmar que a construção do imaginário social brasileiro é marcada por uma perspectiva que ora silencia completamente sobre a África e os africanos, ora os percebe como sinônimos do atraso e da barbárie. No Brasil, no campo intelectual, o interesse pela África se construiu apenas na medida em que ela contribuiu para a formação do país. A realidade sociocultural do continente africano só interessou aos principais personagens de nossa história intelectual quando tal realidade os ajudava a compreender o que chamavam de uma “África brasileira” (VILHENA, 1997).

É comum os estudantes se depararem com percepções generalizantes nas quais o seu continente desponta como um todo homogêneo, destituído da imensa singularidade e diversidade que lhe é característico, como se fosse um único lugar.

Eles pensam que nós somos um Estado. Eles não sabem que a África é um continente. Eles pensam que a África é um país só. Então o que eles veem na televisão, que a televisão mostra aquela coisa de pobreza, guerra, pegam isso como se fosse África em geral. Pessoa fala: 'ah, vocês comiam pedra lá, agora você está...' Por exemplo, eu fui fazer academia. O pessoal fala. Pessoal fala: 'olha só como é que está, chegou aqui magro, agora tá com...'. Esse tipo que pessoas têm com você. (E, 1, B).

Depois que eu cheguei aqui, com as perguntas das colegas, às vezes na universidade, que eu comecei a associar as coisas. A visão que às vezes a gente tem de um determinado país, e da raça. Porque assim quando chegamos, quando cheguei aqui, eu era angolana. Às vezes, na rua, as pessoas perguntam: 'você é angolana?' 'Não, eu sou guineense.' Eles só conheciam Angola. Angola é capital da África. África é um país, não um continente. Então, às vezes, quando você vai explicar que não é isso que eles estão pensando, parece que eles sabem mais que você. $(\mathrm{E}, 9, \mathrm{C})$.

Que às vezes, na rua, você passa ali, a pessoa te para e te pergunta, faz um a pergunta que você vê 
que não tem nem sentido. Primeira coisa que eles perguntam é coisa que a mídia mostra: 'Ah, ontem eu vi no seu país, está sofrendo muito, muita fome, muita miséria.' Eu pergunto, porque eles já falam país, não falam continente. Que eles falam qualquer que é África. África é continente, não país. Primeira coisa, sou da Guiné Bissau. O que a mídia mostra não falo que não é uma coisa real, mas só que não pode ser generalizado. $(\mathrm{E}, 4, \mathrm{C})$.

É possível que as percepções generalizantes, nas quais a África é vista como um todo homogêneo destituído da imensa singularidade e diversidade, como se fosse um único lugar, sejam uma das razões pelas quais os estudantes, que antes se percebiam a partir da cidade, país ou etnia de origem, passam a se autodeclararem indistintamente como "africanos". Apesar de serem, tal como todas as pessoas da contemporaneidade, dotados de múltiplas identidades (APPIAH, 1997), no contexto de inserção e permanência no Brasil, passa a valer a identidade continental, identidade segundo a qual os estudantes se definem e são definidos, unicamente, como africanos. Contudo, "africanos" pode, em determinados momentos, adquirir uma conotação pejorativa e estigmatizante (SUBUHANA, 2005). Para Gusmão (2012), "africanos" é uma categoria genérica, desprovida de especificidade. Contudo, tal categoria genérica e indistinta se refere a grupos que conformam coletividades, no sentido de um grupamento de indivíduos que possuem a mesma procedência, já que nascidos na África, porém de diversos contextos nacionais, étnicos e tribais (BAUNGARTEN, 2004 apud GUSMÃO, 2012). Todavia, a inclusão na categoria africana não é aceita passivamente pelos estudantes. Ver-se e sentir-se como africano é algo que é incorporado no Brasil (HIRSCH, 2007), mas não para todos.

Engraçado que já discuti com uma menina, que ela me chamava de africano. É claro que sou africano mesmo. No início eu deixava, agora eu não deixo qualquer alguém falar. Falo: 'não sou africano, sou angolano.' 'Mas como você não é africano? Você é angolano?' Eu replico a pergunta: 'você é americano?' Eles falam: 'não, sou brasileiro.' Eu falo: 'eu sou angolano; no passaporte, nos meus documentos, em nenhum lugar você vai ver africano. Todos são angolano, angolano, angolano. Minha nacionalidade é angolana. Então que nem você, você não é americano, latino. Você não identifica pelo continente. Você se identifica pelo seu país.' Então, muitas pessoas, ofato das pessoas chamarem de africano, as pessoas pensam que a África é um país, é como se fosse uma nacionalidade que a gente possui. (E, 6, B).

As entrevistas nos permitem afirmar que, tal como aponta Appiah (1997, p. 251), ser africano é "um dentre muitos outros modelos destacados de ser". O autor afirma que:

[...]cada um de nós, pertence a um grupo com costumes próprios. Admitir que a África, sob esses aspectos, possa ser uma identidade utilizável é não esquecer que todos pertencemos a comunidades diversificadas, com seus costumes locais [...]. 'Africano' certamente pode ser uma insígnia vital e capacitadora; mas, num mundo de sexos, etnicidades, classes e línguas, de idades, famílias, profissões, religiões e nações, mal chega a surpreender que haja ocasiões em que ela não é o rótulo de que precisamos. (APPIAH, 1997, p. 251).

Os estudantes são, tal como a descrição de Appiah (1997), heterogêneos, apesar de não serem percebidos como tal. Diante dos percursos e processos vivenciados é provável que sejam portadores de uma hibridez cultural (RUSHDIE, 1994).

Nas cidades de Cuiabá e Brasília, outro elemento a partir do qual os estudantes passaram a ser agrupados indistintamente foi a cor da pele. Desde o afluxo de haitianos no Brasil, tornaram-se corriqueiras as situações nas quais são confundidos com os imigrantes. Segundo a percepção dos estudantes, o fato de serem todos "pretos" faz com que sejam vistos indistintamente como se fossem os mesmos, oriundos de um único local.

Não, alguns acham assim, por exemplo, eles entendem, mas acho que não é culpa deles. Eles entendem que África é um país. Você tenta, às vezes você tenta explicar e ele teima ainda, entendeu? Você tenta falar: 'não', tem alguns que teimam. Você tenta falar para eles: 'não, eu sou de Guiné', 'Mas não é a mesma coisa?' Eles falam dos haitianos: 'Você é haitiano?' 'Não, sou de África ou eu sou de Guiné.' 'Não é a mesma coisa?' Não é a mesma coisa, entendeu? Então, é falta de conhecimento, entendeu? Os caras teimam ainda, e você tentando explicar, o cara teima. Ele o quê, porque você é preto. Então, significa todos os pretos são a mesma coisa. 'Não 
são do mesmo país? Não.' Quando, por exemplo, vocês aqui da América, Estados Unidos, Brasil ou Argentina. Às vezes, eu falo: 'Brasil com Argentina é mesma coisa?' Fala: Não.' Pergunto assim: 'Você é argentino?' O cara já pula fora. Falo: 'Viu, é a mesma coisa, entendeu?' Você, pergunta o cara: 'Você haitiano', 'Não, sou africano.' 'Mas não é a mesma coisa?' 'Não, haitianos são americanos.' A maioria não sabe. 'Não', você fala. Já respondem: 'Não é a mesma coisa?!' (E, 1, C).

A origem africana certamente é um diferencial nas relações sociais, principalmente quando nos referimos ao que se fala e se pensa sobre o africano, a imagem construída e disseminada. Porém, a cor da pele aparece como um elemento agrupador. O que se pode afirmar a partir disso é que, ora os estudantes são vistos porque são africanos, ora porque são negros. Tanto em Brasília quanto em Cuiabá, a cor da pele faz com que muitos estudantes sejam imediatamente vistos como haitianos, o que demonstra a fragilidades dos conhecimentos brasileiros sobre o "Sul" do mundo. Segundo os estudantes, é comum as pessoas não distinguirem a diferença entre a África, um continente, e o Haiti, um país. Numa situação de sala de aula em Brasília, um estudante guineense ouviu a referência "Esses haitianos da África":

Muitas das vezes, hoje, ainda acontece isso. Você sai na rua: 'Oi, você é haitiana?' Falo: 'Não.' A pessoa já chega e fala para você: 'Você é haitiana?' 'Não, eu sou guineense' 'Mas é lá perto' 'Não, o Haiti está na América. O Haiti é mais perto do Brasil do que da Guiné. O Haiti está no continente americano. Guiné Bissau está no continente africano.' 'É um pouco longe ou é a mesma coisa?' Você percebe o quanto é a ignorância, o quanto é o distanciamento desse olhar, porque o Brasil, o Paraguai, a Bolívia é a mesma coisa? 'Está pertinho?' 'O Haiti está na América Central, quer dizer, faz parte do continente onde o Brasil se localiza.' A pessoa ainda te fala: 'Mas é perto, não é?" Por quê? A ignorância de muitos, eles ligam a cor, porque eu sou negra, o haitiano é negro, é a mesma coisa. (E, 7, C).

$\mathrm{Na}$ maior parte do tempo, os estudantes foram obrigados a lidar com uma percepção indistinta sobre eles mesmos como africanos, ou seja, pela origem continental, que na percepção de seus interlocutores é um país. Com a entrada de imi- grantes haitianos no Brasil, a cor da pele passa a ser um referencial de origem e identidade, porém incorrendo-se no erro da indistinção e generalização. Pode-se afirmar que, por serem africanos e negros, estejam sujeitos a diferentes estigmatizações, geralmente depreciativas.

As estigmatizações depreciativas podem estar relacionadas às repetidas histórias sobre um povo e um lugar e no hábito de estereotipá-los e percebê-los de forma indistinta, como um todo que, simplesmente por compartilharem a mesma cor da pele ou local de origem, possuem as mesmas características de existência, independentemente de fatores históricos, sociais e culturais. Segundo Adichie (2009), as repetidas histórias que sabemos sobre determinado lugar contribuem para a maneira como o percebemos e, por consequência, tornam-se também uma referência sobre as pessoas daquele lugar. Nesse ambiente, o "Outro" é um ser exótico e, por assim dizer, estranho, do qual apenas ouvimos falar e com quem evitamos nos relacionar. Relacionamo-nos apenas com o que ouvimos a respeito dele,

Nesse sentido, é pertinente o que afirma Adichie (2009) acerca do olhar ocidental sobre a África, um olhar que culmina em uma forma de perceber os africanos. No Brasil, país marcado pela prática da exaltação ao mundo ocidental (PENNA FILHO, 2009), a experiência que o estudante-convênio vivencia denota a presença constante de um estereótipo sobre si e sobre a África, uma única história consagrada como um refrão sobre quem são e sobre o lugar de onde vêm. Bhabha (1998, p. 105, grifo do autor) assevera que "o estereótipo é uma forma de conhecimento e identificação que vacila entre o que está sempre 'no lugar' já conhecido e algo que deve ser ansiosamente repetido". Diante disso, é possível que a percepção brasileira sobre a África seja, antes de tudo, um estereótipo. Assim, para Alves (2015), a expressão "história única" torna-se sinônimo de estereótipo.

\section{Dificuldades como estudante- convênio}

O estudante dos PALOP, ao ingressar no Brasil, se destaca por duas condições: a primeira, aquela na 
qual é um estudante de um programa de convênio no interior de uma universidade brasileira, que não dispõe de estrutura para recebê-lo; a segunda, ser africano e negro no Brasil. A experiência por eles vivenciada impõe muitas dificuldades.

Logo ao chegar ao Brasil, as dificuldades começam por desconhecerem as distâncias geográficas do país; o custo de vida em cada cidade; por pouco ou nada saberem sobre o local onde irão estudar; e pela ausência de uma infraestrutura de recepção e apoio das instituições envolvidas na articulação do programa. A experiência do ingresso é marcada pela falta de orientação, informação e preparo sobre o PEC-G, a cidade, a universidade, sua estrutura e funcionamento e as informações básicas que os subsidiem até estarem plenamente familiarizados com o espaço universitário.

Os estudantes enfrentam, ainda, dificuldade de integração; professores indiferentes; discriminação por parte de professores e colegas, dentro e fora da sala de aula, com piadas, ditados, indiretas; dificuldades de acesso a materiais; exclusão nos grupos de trabalho; muitas exigências para receber bolsa; atrasos no recebimento de bolsas; desconhecimento da organização do trabalho burocrático e pedagógico da universidade; adaptação e integração ao meio social e acadêmico; falta de acompanhamento pedagógico; carência de apoio psicológico e moral, bem como falta de incentivo. A principal estratégia para resolver e lidar com as dificuldades de inserção e instalação em um novo lugar, nesse contexto, é a construção das redes sociais. Essas redes, muitas vezes, começam a ser articuladas lá, antes do início da partida, quando da publicação dos selecionados pelo programa naquele ano.

No decorrer da estadia os estudantes ainda encontram problemas com a língua portuguesa; pressupõe-se que a língua comum favoreceria as relações entre estudantes africanos e brasileiros, bem como facilitaria a vida acadêmica. No entanto, a língua é mais um dos aspectos ao quais os estudantes, mesmo sendo de países de língua oficial portuguesa, necessitam adaptar-se. Segundo Morais e Silva (2011), a língua portuguesa, tal como se expressa no Brasil, representa um problema, uma vez que este é um dos principais indicadores da sua posição como estrangeiros. São frequentes as dificuldades com o uso da língua, de modo que alguns se sentem envergonhados por temerem repreensões de seus colegas e professores.

\section{Conclusão}

Há pouco, ou nenhum, conteúdo sobre as realidades africanas em todo o sistema de ensino brasileiro. Em um programa voltado a atender os interesses dos países parceiros, seria pertinente que os estudantes tivessem acesso a conhecimentos que contribuíssem para solucionar problemas nas sociedades de origem. Ao contrário disso, o ensino nas instituições brasileiras é acentuadamente etnocêntrico, eurocêntrico e apreciador do modelo ocidental de existência, sendo pouco provável que os conhecimentos aprendidos no Brasil contemplem a realidade dos países de origem. A experiência do estudante é marcada pelo desconhecimento sobre a África, tanto em âmbito institucional, quanto nas relações pessoais. De modo geral, funcionários públicos, professores e colegas de curso pouco ou nada sabem sobre a realidade da África e reproduzem as percepções estereotipadas sobre o continente, circunstância incômoda para os estudantes rotineiramente interpelados por perguntas e questionamentos que apontam ignorância sobre seu continente de origem.

Oficialmente, a aproximação brasileira dos PALOP é impulsionada pela solidariedade fundamentada em vínculos históricos, linguísticos e culturais. Porém, a prática das relações entre os estudantes e os brasileiros, seja nas relações sociais ou em âmbito institucional, é marcada também pelo racismo, discriminação e preconceito racial. No Brasil, sabe-se muito pouco sobre os países africanos e os estudantes passam a conviver com olhares enviesados, que os discriminam em função da cor. Não raro, estão sujeitos a violentas abordagens policiais, para as quais não há nenhuma reprovação por parte das instituições vinculadas ao programa. 


\section{REFERÊNCIAS}

ADICHIE, Chimamanda. O perigo da história única. 2009. Disponível em: $<$ https://www.youtube.com/ watch?v=EC-bh1YARsc $>$. Acesso em: 09/06/2014

ALVES, Iulo Almeida. ALVES, Tainá Almeida. O perigo da história única: diálogos com Chimamanda Adichie. Universidade Estadual do Sudoeste da Bahia. bocc.unisinos.br/pag/alves-alves-o-perigo-da-historia-unica.pdf.

AMARAL, Joana de Barros. Atravessando o Atlântico: o Programa Estudante Convênio de Graduação e a cooperação educacional brasileira. Brasília-DF. 2013. 145 p. Dissertação (Mestrado Acadêmico em Desenvolvimento, Sociedade e Cooperação) - Centro de Estudos Avançados (CEAM), Universidade de Brasília (UnB), Brasília-DF, 2013.

APPIAH, Kwame Anthony. Na casa de meu pai: a África na filosofia da cultura. Rio de Janeiro: Contraponto, 1997.

BHABHA, Homi K. O local da cultura. Belo Horizonte: Editora UFMG, 1998.

BECKER, Howard S. Métodos de pesquisa em Ciências Sociais. São Paulo: Hucitec, 1999.

BRASIL. Ministério das Relações Exteriores. PEC-G: Histórico do Programa. 2015. Disponível em: < http://www. dce.mre.gov.br/PEC/G/historico.php\#tab3>. Acesso em: 20 ago. 2014.

FANNON, Frantz. Pele negra, máscaras brancas. Salvador: EdUFBA, 2008.

GUSMÃO, Neusa Maria Mendes de. África, Portugal e Brasil: um novo Triângulo das Bermudas? Cadernos CERU, série 2, v. 23, n. 2, p. 51-62, dez. 2012.

HIRSCH, Olivia Nogueira. Hoje eu me sinto africana: processos de (re)construção de identidades em um grupo de estudantes cabo-verdianos no Rio de Janeiro. 2007. 220f. Dissertação (Mestrado em Ciências Sociais) - Programa de Pós-Graduação em Ciências Sociais, Pontifícia Universidade Católica do Rio de Janeiro (PUC/RJ), Rio de Janeiro, 2007.

JACCOUD, Luciana; BEGHIN, Nathalie. Desigualdades raciais no Brasil - um balanço da intervenção governamental. Brasília: IPEA, 2002.

KALY, Allain Pascal. O ser preto africano no "paraíso terrestre" brasileiro. Um sociólogo senegalês no Brasil. Lusotopie, p. 105-121, 2001. Disponível em: <http://www.lusotopie.sciencespobordeaux.fr/kaly.pdf>. Acesso em: 11 jan. 2015.

MINAYO, Cecília de Souza (Org.). Pesquisa social: teoria, método e criatividade. Petrópolis, RJ: Vozes, 2007.

MORAIS, Sara Santos; SILVA, Kelly Cristiane. Estudantes de países africanos de língua oficial portuguesa nas universidades brasileiras: tensões de sociabilidade e dinâmicas indenitárias. In: CONGRESSO LUSOAFROBRASILEIRO DE CIÊNCIAS SOCIAIS, 9., 2011, Salvador. Anais... Salvador: Universidade Federal da Bahia (UFBA), 2011.

MÜLLER, Maria Lúcia Rodrigues. et al. Educação e diferenças: os desafios da Lei 10.639/03. Cuiabá: EdUFMT, 2009.

NOSOLINI, Elber Eugéni O. Brasil e os países africanos de língua oficial portuguesa: aproximação, distanciamento e reaproximação (de 1975 aos dias atuais). 2004. Dissertação (Mestrado em Relações Internacionais) - Universidade de Brasília (UnB), Brasília, DF, 2004.

NUNES, Maria Madalena. AMI ÚNICO, SUMA BO: as construções de identidades entre estudantes guineenses, caboverdianos e são tomenses do Programa Estudante de Convênio de Graduação da Universidade Federal de Mato Grosso. Cuiabá: EdUFMT, 2013.

OJIMA, Ricardo. et al. Migrações internacionais motivadas por estudo: uma análise sociodemográfica dos estudantes estrangeiros radicados no Brasil. Revista PerCursos, Florianópolis, v. 15, n. 28, p. 166-189. jan./jun. 2014.

OLIVEIRA, Verônica Macário de; MARTINS, Maria de Fátima; VASCONCELOS, Ana Cecília. Entrevistas "Em Profundidade" na pesquisa qualitativa em administração: Pistas teóricas e metodológicas. In: SIMPÓSIO DE ADMINISTRAÇÃO DA PRODUÇÃO, LOGÍSTICA E OPERAÇÕES INTERNACIONAIS - SIMPOI, 15., 2012, São Paulo. Anais... São Paulo: Fundação Getúlio Vargas (FGV), 2012. p. 1-12.

PAIXÃO, Marcelo J. P. Desenvolvimento humano e relações raciais. Rio de Janeiro: DP \& A, 2003.

PENNA FILHO, Pio. A África contemporânea - do colonialismo aos dias atuais. Brasília, DF: Hinterlândia, 2009. 
RUSHDIE, Salman. Pátrias imaginarias. Lisboa: Publicações Dom Quixote, 1994.

SARAIVA, José Flávio Sombra. África parceira do Brasil Atlântico: relações internacionais do Brasil e da África no início do século XXI. Belo Horizonte: Fino Traço, 2012.

SUBUHANA, Carlos. Estudar no Brasil: imigração temporária de estudantes moçambicanos no Rio de Janeiro. 2005. Tese (Doutorado em Serviço Social) - Escola de Serviço Social da Universidade Federal do Rio de Janeiro (UFRJ), Rio de Janeiro, 2005.

TEIXEIRA, Moema De Poli. Relações raciais na sociedade brasileira. 2. ed. rev. e ampl. Cuiabá: UAB/EdUFMT, 2010

Relações raciais na sociedade brasileira. Cadernos Penesb - Periódico do Programa de Educação sobre o Negro na Sociedade Brasileira, Rio de Janeiro/Niterói, n. 7, p. 261-284, nov. 2006.

ULLRICH, Regina Danielle; CARRION, Rosinha Machado. A cooperação brasileira na área da educação nos PALOPS no período 2000-2012: principais atores e projetos. In: ENCONTRO NACIONAL DA ASSOCIAÇÃO BRASILEIRA DE RELAÇÕES INTERNACIONAIS, 4., 2013, Belo Horizonte. Anais... Belo Horizonte: Pontifícia Universidade Católica de Minas Gerais (PUC/Minas), 2013.

VILHENA, Luís Rodolfo. Ensaios de Antropologia. Rio de Janeiro: EdUERJ, 1997.

Recebido em: 26.01 .2016

Aprovado em: 01.03.2016 